\title{
Case Study: Improvement of course outcome of Elements of Electrical and Electronics Engineering with the help of innovative teaching methodologies and changes in laboratory experiments
}

\author{
Deepa Jain ${ }^{1}$, Sonia Joshi ${ }^{2}$ \\ ${ }^{1}$ Department of Electronics Engineering, K J Somaiya College of Engineering, Mumbai, India \\ ${ }^{2}$ Department of Electronics Engineering, K J Somaiya College of Engineering, Mumbai, India \\ 1deepajain@somaiya.edu \\ ${ }^{2}$ soniajoshi@somaiya.edu
}

\begin{abstract}
:
Application of innovative methods and industry-oriented curriculum is currently the basic requirement for teaching the engineering graduates. It helps the students to attain the practical and industry specific knowledge in their gradual learning process. Innovative ways of teaching are required from foundation year of engineering curriculum so that the students can co-relate the laboratory experiments with dayto-day life and can be motivated towards research-based thought process. This case study discusses about the innovative changes in teaching methodology from theorybased laboratory experiments to next generation application-based laboratory experiments which connects students with day to day life. This research primarily deals with changes in laboratory setup, teaching methodologies and laboratory experiments and its impact on course outcome of engineering students. The feedback of students show encouraging results in improving course out comes with the help of innovative teaching methodologies.
\end{abstract}

Keywords: Course Outcomes, Outcome Based Education, assessment tools, control system

\section{Introduction and Objective}

"The ideal engineer is a composite ... He is not a scientist, he is not a mathematician, he is not a sociologist or a writer; but he may use the knowledge and techniques of any or all of these disciplines in solving engineering problems."

— Nathan W. Dougherty, American Civil Engineer

As the quotation says success of engineering education lies in application of engineering knowledge for solving complex engineering problems. Complex engineering problems often require application of knowledge from different engineering streams and disciplines. This has been observed by the engineering institutes that it is difficult to motivate an undergraduate engineering student of one discipline to inculcate interests in subjects of other disciplines. First year curriculum in engineering gives importance to studies in different engineering disciplines to prepare students for future industries. So, electrical and electronics laboratory (EEE) is a mandatory course to be studied for building engineers. The solution of this problem is not in applying different measures or increasing course material and experiments but on its successful implementation by designing the laboratory course in innovative, industry specific and application-oriented manner. This practical approach can generate interest, motivation and passion for engineering studies. It helps students to learn the basics of science in practical manner and have lifelong impact on their minds. More emphasis is to be given to outcome based learning so that the student finds the designed curriculum interesting and innovative. Outcome-Based Education (OBE) approach is one of student-centric learning methods that focus on measuring student performance. [2], [1]

Researchers have found some of the advantages of an OBE approach which are mentioned as follows

a) Quality of the graduates produced

b) Development of more systematic, innovative and flexible teaching methods

c) Increase in student exposure to professional practice through internships and projects [3] so that every graduate is supposed to acquire attributes in knowledge, skill and attitude domain.

Each program defines program outcomes (POs) which are assessed and evaluated at the end of four years of graduation. These attributes are taken care by course outcomes (COs) which are defined for every course and evaluated in every semester. Hence, attainment of COs is the focus of teaching learning process in OBE approach $[5]$. 
OBE approach means a commitment not only to provide an opportunity of education and promotion but a commitment that all students will ultimately reach with the same minimum standards. The methods of content delivery and assessment tools has to be properly developed. [4]

It is observed through feedback and analysis obtained from students of two consecutive years that by redesigning the laboratory experiments and courses, we can generate interest, motivation and passion in the minds of engineering students. Thus, the engineering students can work on skill development and practical industry knowledge rather than only focussing on clearing the subject.

The most important factor in the study was to change the perception regarding laboratory experiments so that best outcomes can come with minimum hard work. Since, in autonomous college there is a provision of change in curriculum design as per National Board of Accreditation (NBA) guidelines, so we initiated the changes in the theory curriculum to meet the targets of course outcomes and to keep laboratory setup and experiments list at par with industry standards. In order to achieve this, new experiment list is prepared so that students develop interest regarding laboratory work. Also, students faced problems in understanding the applications of the theorem and its relevance to the industry.

\section{Methodology}

The need for this research work has evolved from the thought process that how mechanical engineering graduates can have interest in the electrical and electronics engineering laboratory. We started by revisiting our experiments list and then redesigning the experiments and course. This research involves the study on a group of students from mechanical engineering program for two consecutive years in academically autonomous college affiliated to University of Mumbai. The sampling methodology is convenience sampling. First year mechanical engineering students of 2017-18 and 2018-19 for observation and analysis. In order to understand the effectiveness of study the following research question is:

RQ1: Do the First year students can correlate and apply their basic knowledge of Electrical and Electronics engineering (EEE) with the day-to-day life applications.

By taking into consideration the observations of EEE in previous year (2017-18). The following corrective measure were taken in the subsequent year (2018-19)

List of Corrective Measures

1) Modification in Laboratory Experiment List: Addition of more simplistic but more applicationoriented experiments.
2) Use of LTspice Simulation software: Electrical Network Theorem were explained by use of software tools

3) Study and Presentation on different kind of lamps that has incorporated think pair and share.

4) Mini projects (circuits on paper submission) on DC motors.

List of experiment Electrical and Electronics Engineering (EEE) year (2017-18)

1) Mesh and Nodal analysis

2) Full wave rectifier

3) Thevenin's \& Norton's Theorem

4) Maximum Power Transfer Theorem

5) R-L-C series and parallel circuit

Revised List of experiments Electrical and Electronics Engineering (EEE) year (2018-19)

1) Battery level Indicator: Deals with concepts of Voltage and Current division

2) Mobile Battery Charger: Analyse the concept of power supply and gives application of Rectification.

3) Impendence Matching

4) Calculate the Power factor in series RLC Circuit

5) Improvement Power factor in Parallel RLC Circuit (i.e. currently used in Industry)

\section{A. System of Evaluation and Assessment}

\section{1) Course Outcome}

Following are the course outcomes of EEEE used in 2017-18 and 2018-19 which covers the curriculum and sets objectives.

TABLE 1: COURSE OUTCOMES OF EEEE

\begin{tabular}{|c|l|}
\hline $\begin{array}{c}\text { Course } \\
\text { Outcome }\end{array}$ & $\begin{array}{l}\text { After successful completion of the } \\
\text { course students should be able to }\end{array}$ \\
\hline CO1 & $\begin{array}{l}\text { Analyze resistive networks excited by } \\
\text { DC sources using various network } \\
\text { theorems }\end{array}$ \\
\hline CO2 & $\begin{array}{l}\text { Demonstrate and analyze response of } \\
\text { series - parallel combinations of R-L-C } \\
\text { circuits excited by single phase AC } \\
\text { source }\end{array}$ \\
\hline CO3 & $\begin{array}{l}\text { Analyze three phase AC star and delta } \\
\text { connections for resistive, inductive and } \\
\text { capacitive loads. }\end{array}$ \\
\hline CO4 & $\begin{array}{l}\text { Understand principles and working of } \\
\text { AC machines and DC machines with } \\
\text { their applications. }\end{array}$ \\
\hline CO5 & $\begin{array}{l}\text { Explain rectifier-filter circuits using PN } \\
\text { junction diode and working of Bi-polar } \\
\text { junction transistor. }\end{array}$ \\
\hline
\end{tabular}

Target is set at $60 \%$ with the understanding that every student should gain at least $60 \%$ marks to attain the objective of the course outcome. 
Various Assessment tools were developed with careful mapping to course outcomes. The schedule Syllabus and date of submission is told to students well in advance. The scheme of assessment is also given to the students.

\section{1) In assessment of COs the weightage of direct assessment tools is $80 \%$.}

- Internal Assessment_1: Open Software tool was explained to students in the class. Three questions were given based on electrical network theorem such that every student had to perform simulation by changing the load $\mathrm{R}_{\mathrm{L}}$ according to their roll numbers and submitting the simulation results with the circuit. This concept of internal assessment was introduced in the year 2018-19 and marks were assigned to this kind of activity.

- Internal Assessment_2: Mini projects on paper based on DC motor was introduced. We assigned a mini project to the group of six students based on DC motor. So, they studied the applications of DC motor as well as its working principle.

- $\quad$ End semester Laboratory Examination: At the end of the semester all the students must appear for an oral examination covering complete syllabus. These were conducted in both academic years 2017-18, 2018-19.

\section{II) Indirect Assessment Tools}

At the end of every semester; Course exit questionnaire was administered through Learning Management System. The students were given one week duration for completion of the survey. This was an unbiased survey given by students individually. These exercises were conducted in both academic years 2017-18, 2018-19.

In assessment of COs the weightage of direct tools is $20 \%$.

\section{III) Data gathered}

The following is the gathered data for analysis at the completion of the study.

- The Marks obtained by students in Oral/Practical examination of Electrical and Electronics Engineering Laboratory in two consecutive academic year (2017-18 and 2018-19).

- The marks obtained by students of EEE during 201819 in semester evaluation of on open source Software simulation

- $\quad$ The marks obtained by students of EEE during 201819 in semester evaluation of on paper mini projects.

- Comparison of CO assessment of EEE Laboratory in 2017-18 and 2018-19.

- Student responses to the survey questions.

\section{Results}

A. Marks of EEE Laboratory (2017-18)

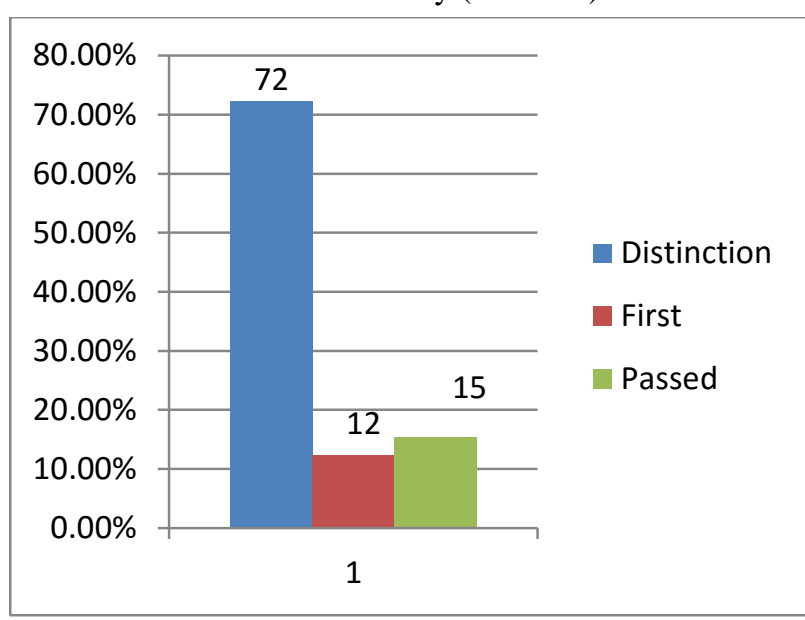

Figure 1.1 Performance of students in End Semester Oral/Practical in 2017-18

Marks of EEE Laboratory (2018-19)

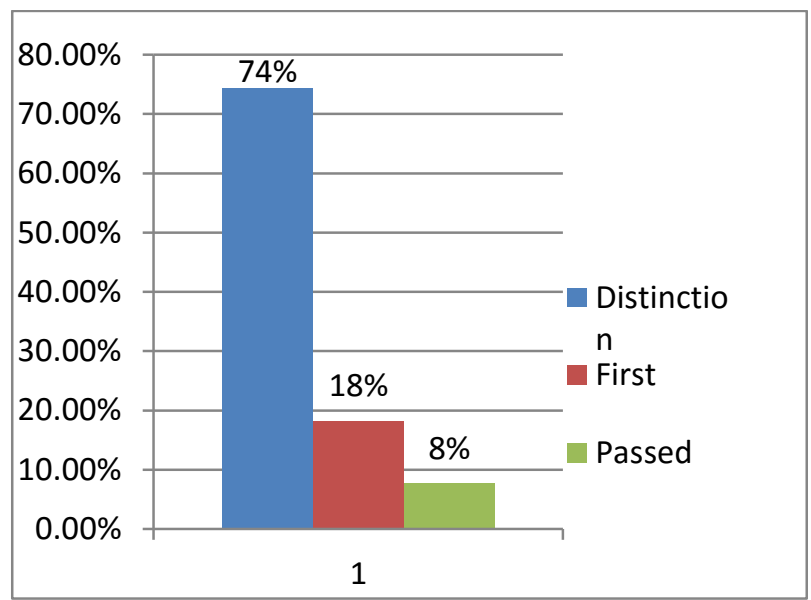

Figure 1.2 Performance of students in End Semester Oral/Practical in 2018-19

B. Performance of students in Internal Assessment 1 Addition of software simulation is also a part of innovative teaching learning. IA1 were also given related to $\mathrm{CO} 1$

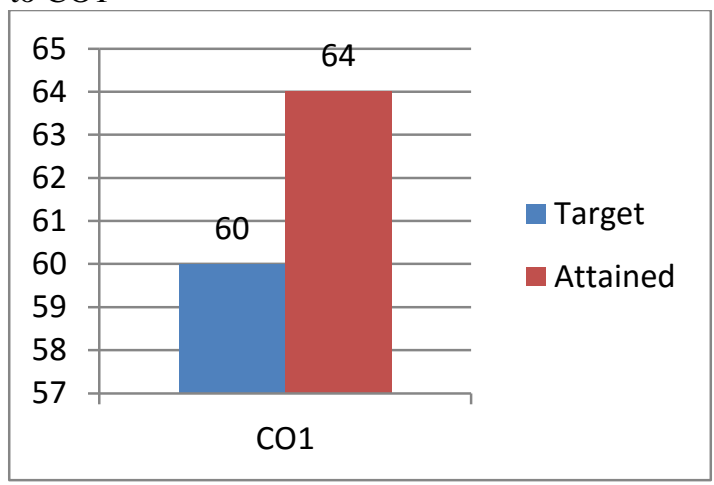

Figure 2 Analysis of student's performance in Software Simulation 
C. Performance of students in Internal Assessment 2

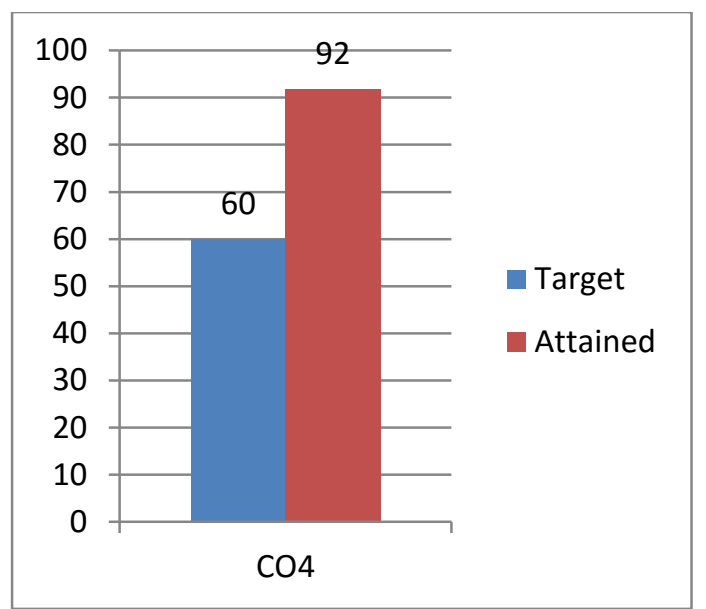

Figure 3 Analysis of performance of students in on paper mini project

D. Comparison of $\mathrm{CO}$ attainment of Electrical laboratory in 2017-18 and 201-19

It was our aim to improve the attainment of all CO's except CO5 academic year 2018-19. If we see the efforts and the results of the analysis, then it this shows the continuous improvement.

This was reflected in the final $\mathrm{CO}$ analysis for two consecutive academic years for EEE.

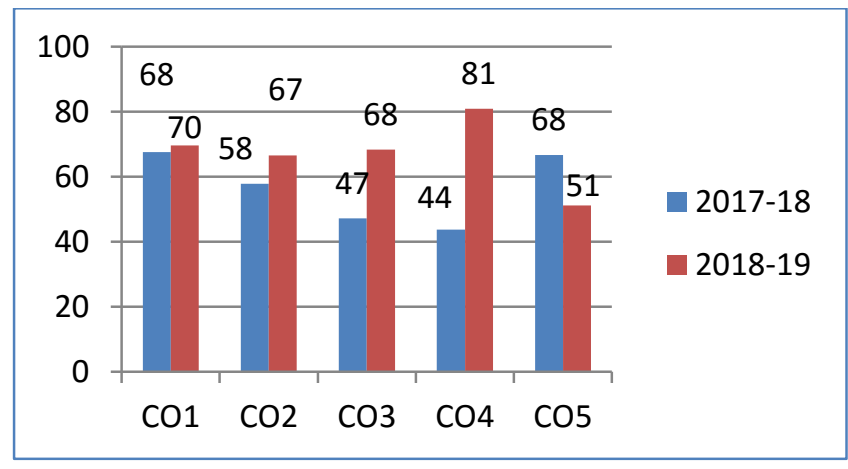

Figure 5: Comparison of Course Outcome (CO) attainment in 20178 and 2018-19

E. Student Responses

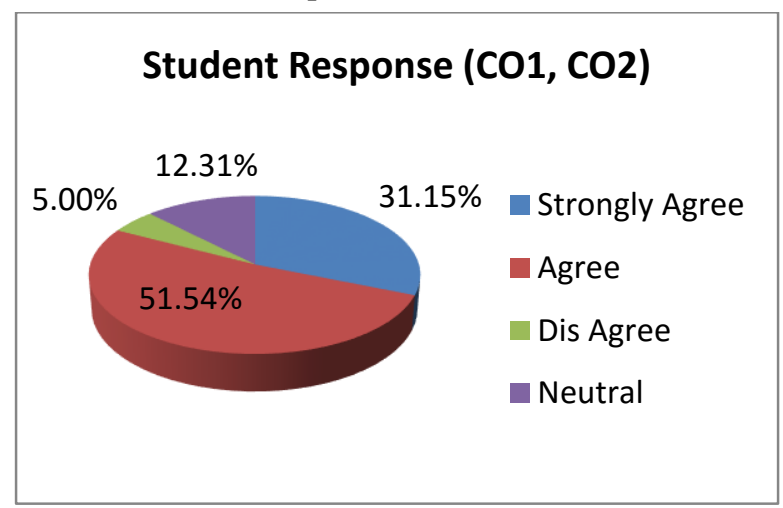

Figure 6a): Shows analysis of student's responses for course outcomes in percentage terms for $\mathrm{CO} 1, \mathrm{CO} 2$.

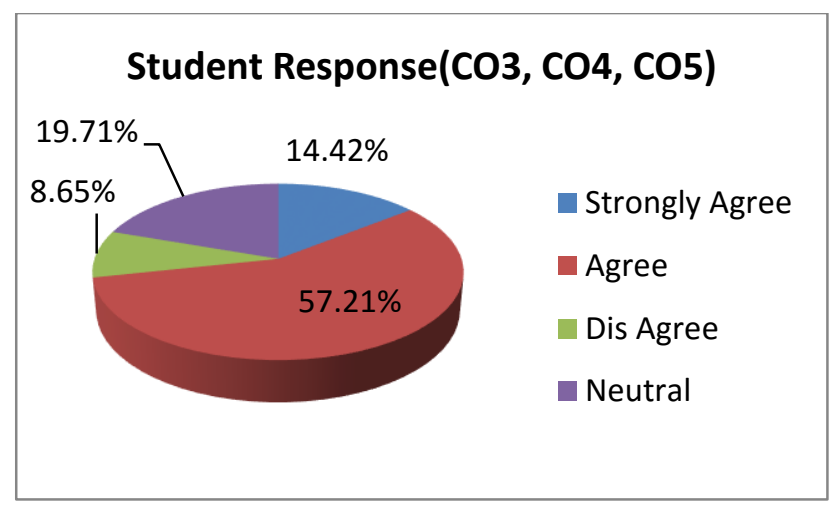

Figure 6b): Shows analysis of student's responses for course outcomes in percentage terms for $\mathrm{CO3}, \mathrm{CO} 4, \mathrm{CO5}$ 
TABLE2: SUMMARY OF STUDENT RESPONSES:

\begin{tabular}{|c|c|c|c|c|c|}
\hline \multirow[b]{2}{*}{$\begin{array}{c}\text { Course } \\
\text { Outcome }\end{array}$} & \multirow[b]{2}{*}{ Question asked } & \multicolumn{4}{|c|}{ \% of students } \\
\hline & & $S A$ & $A$ & $D A$ & $N$ \\
\hline \multirow{3}{*}{$\mathrm{CO1}$} & $\begin{array}{l}\text { Are you able to apply Mesh and nodal analysis while } \\
\text { solving problems in an electrical circuit? }\end{array}$ & $44.23 \%$ & $44.23 \%$ & $3.85 \%$ & $7.69 \%$ \\
\hline & $\begin{array}{l}\text { Do you think that Thevnin theorem, Nortons Theorem is } \\
\text { useful to solve complicated electrical circuit? }\end{array}$ & $32.69 \%$ & $51.92 \%$ & $3.85 \%$ & $11.54 \%$ \\
\hline & $\begin{array}{l}\text { Rate your understanding in using star-delta / delta-star } \\
\text { transformation for a DC network. }\end{array}$ & $42.31 \%$ & $46.15 \%$ & $3.85 \%$ & $7.69 \%$ \\
\hline \multirow{2}{*}{$\mathrm{CO} 2$} & $\begin{array}{l}\text { Could you able to analyze the series and parallel RLC AC } \\
\text { Circuits? }\end{array}$ & $25.00 \%$ & $61.54 \%$ & $3.85 \%$ & $9.62 \%$ \\
\hline & $\begin{array}{l}\text { Are you able to understand power factor improvements } \\
\text { method for Ac Circuits? }\end{array}$ & $11.54 \%$ & $53.85 \%$ & $9.62 \%$ & $25.00 \%$ \\
\hline $\mathrm{CO3}$ & $\begin{array}{l}\text { Are you able to understand the difference between the three } \\
\text { phase and single phase power supply? }\end{array}$ & $17.31 \%$ & $57.69 \%$ & $5.77 \%$ & $19.23 \%$ \\
\hline \multirow{2}{*}{$\mathrm{CO} 4$} & $\begin{array}{l}\text { Could you understand the importance of Transformers in } \\
\text { real time applications? }\end{array}$ & $9.62 \%$ & $55.77 \%$ & $11.54 \%$ & $23.08 \%$ \\
\hline & $\begin{array}{l}\text { Are you able to understand the different applications of DC } \\
\text { Motors? }\end{array}$ & $7.69 \%$ & $57.69 \%$ & $9.62 \%$ & $25.00 \%$ \\
\hline \multirow[t]{2}{*}{ CO5 } & $\begin{array}{l}\text { Do you agree that transformation of AC into DC has } \\
\text { various applications in our daily life? }\end{array}$ & $23.08 \%$ & $57.69 \%$ & $7.69 \%$ & $11.54 \%$ \\
\hline & $\begin{array}{l}\text { How far you are able to co-relate lab experiments with day } \\
\text { to day life? }\end{array}$ & \multicolumn{4}{|c|}{ Very Positive feedback from students } \\
\hline
\end{tabular}

\section{Conclusions}

Through this study we have tried to answer following research question:

RQ1: Do the First year students can correlate and apply their basic knowledge of Electrical and Electronics engineering (EEE) with the day-to-day life applications.

We can conclude from the research work during two academic sessions that the learning experience and understanding of applications of lab experiments is much better for students by introducing innovative teaching methodologies and application-oriented experiments, exposure to simulations and by introducing mini projects for real time applications. Engineering students are able to co-relate the laboratory experiments with day-to-day life and are motivated towards research based thought process with the help of innovative teaching methodologies.

Following are the key observations based on research data:

5. Performance of students in internal assessments increased by $50 \%$.

6. $64 \%$ course objective for year $2018-2019$ was attained as compared to target of $60 \%$.

7. Number of distinctions and first class increased from $84 \%$ to $92 \%$ for $2017-2018$ and $2018-2019$ respectively.

8. The Course outcomes for $\mathrm{CO} 1, \mathrm{CO} 2, \mathrm{CO} 3$ and $\mathrm{CO} 4$ increased while it reduced for $\mathrm{CO}$.
9. Course Outcome agreement for 2018 -2019 was $87 \%$, $76 \%, 75 \%, 65 \%$ and $81 \%$ for $\mathrm{CO} 1, \mathrm{CO} 2, \mathrm{CO} 3, \mathrm{CO} 4$ and $\mathrm{CO} 5$ respectively.

10. From the results obtained in laboratory components and internal assessment (IA), it is seen that almost $78 \%$ students are able to perform in direct assessment tools.

11. It is also observed that the presentations given by the students have helped them to work as one team. Team building skills of students were increased.

12. The attainment of Course Outcomes has also improved.

In the response of survey conducted, more than $90 \%$ of students feel that course contents are useful in future to design their projects and research work. More than $80 \%$ students feel that they learnt the concepts better by performing application-based experiments and simulations. However, the corrective measures were taken in 2018-2019 and the observations are based on our first experience. It will not be appropriate to concretely put forth these observations as conclusions. They can be substantiated only after sufficient time. The observations are impacted by external factors beyond the control of experimental study. 


\section{Acknowledgement}

We would like to sincerely thank following team members who have provided continuous guidance and support for this research work:

Principal - KJ Somaiya College of Engineering, Head of Department - Electronics Engineering KJ Somaiya College of Engineering and Faculty members who have jointly conducted this course in First Year Bachelor of Technology.

\section{References}

1. Parveen P Terangl, Sanjiba Kr. Bisoyi, Vinay Kumar Chandna (2015),"Weightage factor analysis between Programme Outcomes and Course Outcomes: A case study", 3rd International Conference on MOOCs, Innovation and Technology in Education (MITE), 8487.

2. Ab Rahim A. A., Thamrin N. M., Abdullah N. E., Hashim H,(2010) "Modem Control Systems in Electrical Engineering Course Assessment Using the Outcome Based Education approach", 2nd International Congress on Engineering Education, Kuala Lumpur, Malaysia $145-150$

3. Crespo R M et. al.(2010), “Aligning Assessment with Learning Outcomes in Outcome-based Education"IEEE EDUCON Education Engineering , Madrid, Spain,.1239-1246.

4. Mecwan A. I., Shah D. G, Fataniya B. D.(2015), "Innovations in Evaluation: An Integral Part of Outcome Based Education", 5th Nirma University International Conference on Engineering (NUiCONE)

5. Dr. D. K. Paliwal, Dr. A. Koteshwara Rao, Dr. S. Bhaskar, Dr. Abudahir and Dr. S. Rajakarunakaran, "Outcome based accreditation", Three day workshop for Evaluators/Resource Person.

http://www.nbaind.org/files/workshops/Three days workshop Outcome based education.pdf 